\title{
Effect of Metformin Therapy Over Hormone Profile in Newly Diagnosed Polycystic Ovary Syndrome -A Nine Months Randomized Controlled Trial
}

\author{
Nazma-Akhtar ${ }^{1}$, *M A Hasanat ${ }^{2}$, Hurjahan-Banu², Sadiqa-Tuqan ${ }^{3}$, Marufa-Mustari $^{2}$, \\ Tania-Sultana ${ }^{2}$, Md Fariduddin ${ }^{2}$ \\ ${ }^{1}$ National Institute of Cardiovascular Diseases (NICVD), Dhaka, Bangladesh \\ ${ }^{2}$ Department of Endocrinology, Bangabandhu Sheikh Mujib Medical University (BSMMU), Shahbag, \\ Dhaka, Bangladesh \\ ${ }^{3}$ Department of Medicine, Square Hospital, Dhaka, Bangladesh \\ hasanatdr@yahoo.com
}

\section{Abstract:}

Background: Polycystic ovary syndrome (PCOS) is a heterogeneous endocrine disorder affecting women of reproductive age. Treatment by metformin is based on the basis of insulin resistance in PCOS.

Objective: To see the effect of metformin therapy for 9 months on hormonal profiles in PCOS.

Methods: Present double blind placebo-controlled study encompassed 80 PCOS subjects (age, mean \pm SD: 23.10 \pm 4.30 ; married/unmarried: 44/36; amenorrhea/oligomenorrhea: $90 \%$; abortion: 25\%; infertility: $38.6 \%$ ) who were tested for hormonal profiles (serum testosterone, progesterone and anti-mullerian hormone, $\mathrm{AMH}$ ) at recruitment and after 9 months of therapy with metformin/placebo having $>80 \%$ compliance. Among 80,49 completed the study (metformin $=26$, placebo $=23$ ), 4 became pregnant before reaching the end point (metformin=1, placebo=3), and 27 dropped out (metformin=13, placebo=14). AMH was assayed by ELISA whereas testosterone and progesterone by chemiluminescent method.

Results: Baseline characteristics as well as hormonal and biochemical profiles were statistically similar between metformin and placebo groups. After 9 months, AMH (ng/ml) increased significantly in both metformin $(6.10 \pm 5.68$ vs. $8.67 \pm 4.27, \mathrm{p}<0.003)$ and placebo $(4.89 \pm 3.70$ vs. $10.54 \pm 3.58, \mathrm{p}<0.001)$ groups. Progesterone $(1.55 \pm 2.58$ vs. $5.16 \pm 5.20, \mathrm{ng} / \mathrm{ml}, \mathrm{p}=0.006)$ increased whereas testosterone significantly decreased $(8.11 \pm 3.98$ vs. $5.96 \pm 1.72, \mathrm{ng} / \mathrm{ml}, \mathrm{p}=0.003)$ in the metformin group. Unlike metformin, testosterone $(8.88 \pm 3.10$ vs. $8.86 \pm 3.06, \mathrm{ng} / \mathrm{ml}, \mathrm{p}=0.989)$ and progesterone $(0.94 \pm 0.85 \mathrm{vs} 0.82 \pm 1.34, \mathrm{ng} / \mathrm{ml}, \mathrm{p}=0.670)$ were unchanged in placebo. Side effect like loose motion, abdominal pain, nausea and vomiting were observed during the initial part of therapy in both groups.

Conclusions: The present double-blind placebo-controlled RCT of nine months revealed that metformin has significant beneficial effect on androgenous activity of PCOS.

Keywords: PCOS, Metformin AMH, Testosterone, Progesterone.

\section{INTRODUCTION}

Polycystic ovary syndrome (PCOS) is a heterogeneous endocrine disorder of women with multifactorial causes leading to chronic anovulation associated with androgen excess. It was first described by Stein \& Leventhal in 1935 as the commonest endocrine disorder in women of reproductive age leading to menstrual irregularity, which is one of the cardinal clinical features of PCOS.1 Incidence of PCOS in women of reproductive age is 
Effect of Metformin Therapy Over Hormone Profile in Newly Diagnosed Polycystic Ovary Syndrome -A Nine Months Randomized Controlled Trial

reported to be 5 to $10 \%$ which is found to be increasing than assumed. ${ }^{2}$ PCOS is characterized by anovulatory menstrual cycle, infertility, hyperandrogenism thus resembling different metabolic syndromes. ${ }^{3}$ In 2003 Rotterdam criteria was proposed which requires two of the following characteristics for the diagnosis of PCOS: oligo-ovulation or anovulation, clinical and/or biochemical signs of hyperandrogenism and polycystic ovaries with the exclusion of other etiologies (congenital adrenal hyperplasia, androgen secreting tumors, Cushing syndrome). ${ }^{4}$ Women with PCOS may present with multiple manifestation which include cutaneous, reproductive, endocrine and metabolic abnormalities. Cutaneous manifestations including hirsutism, acne and male pattern of baldness are caused by hyperandrogenism. Reproductive manifestations are menstrual dysfunctions like secondary amenorrhea/ oligomenorrhea, infertility, early pregnancy loss and other complication of pregnancy. Metabolic and endocrine abnormalities are increased circulating levels of total and/ or free testosterone, androstenedione, dehydroepiandrostenedione sulfate (DHEAS), decreased sex hormone binding globulin (SHBG), increased insulin level and increased ratio of luteinizing hormone : follicle stimulating hormone (LH/FSH). ${ }^{5}$ In addition to the clinical presentation, PCOS poses the long term risk of development of gestational diabetes, type $2 \mathrm{DM}$, frequent first trimester pregnancy loss and increased risk of cardiovascular disease \& endometrial cancer. ${ }^{6,7}$ Historically, treatment has been directed at ovulation induction for infertility, oral contraceptive or progestins for menstrual irregularity and antiandrogen for hirsutism. ${ }^{9}$ This traditional pharmacological therapy for patients with PCOS mainly address the hyperandrogenic state and anovulation, but neglects the associated long time metabolic risk i.e. insulin resistance.

Recently, increasing evidence has shown that the insulin resistance has an important implication in the pathogenesis of PCOS and the use of insulin sensitizing drugs is an effective therapeutic approach. Insulin resistance with resultant hyperinsulinemia, irrespective of excess weight or frank obesity, has been reported in patient with PCOS. ${ }^{10}$ A growing body of evidence has suggested that hyperinsulinemia contributes to the excess ovarian androgen secretion observed in women with PCOS. ${ }^{11}$ The increase insulin sensitivity by insulin sensitizers may be of therapeutic value in the management of clinical manifestations of hyperinsulinemia and hyperandrogenemia. ${ }^{12}$ The improvement of insulin sensitivity by insulin sensitizers e.g. metformin is now thought to be of pivotal therapeutic value in the management of PCOS.

\section{Materials And Methods}

\section{Subjects}

This was a randomized double blind placebo-controlled study comprised of 80 PCOS patients. Inclusion criteria were: age between 18 and 35 years, PCOS diagnosed on the basis of Revised Rotterdam Consensus 2003 criteria. PCOS patients were recruited consecutively who were given either metformin or placebo in a double blind process and were scheduled for five visits within the period of nine months in each subject, whereupon a window period of 14 days was permitted for the 2nd, 3rd, 4th and last visit. Women with PCOS were treated with metformin for nine months in a dose of $1500 \mathrm{mg}$ daily in three divided doses. 49 patients completed the visit in which 23 were in placebo and 26 in metformin group. On the other hand, who failed to fulfill the compliance, were dropped. Thus 27 were dropped, among them 14 were in placebo and 13 in metformin group; 4 got pregnant, 3 in placebo and 1in metformin group.

\section{Assays}

AMH was estimated by an enzyme-linked immunosorbent assay, AMH GEN II ELISA kit (Beckman Coulter, Inc. USA) whereas other hormones (FSH, LH and Testosterone) by immunochemiluminometric assay. Values of AMH were presented as nanograms per milliliters (conversion factor to $\mathrm{pmol} / \mathrm{l}=\mathrm{ng} / \mathrm{ml} \times 7.1$ ). AMH was calculated using kc3 biograph with help of the standard supplied with the kit. QC (quality control) was used in each assay run to assess precision of the assay. Intra-assay CV (co-efficient of variance) was 3.4 to $5.4 \%$ and inter-assay CV 4.0 to $5.6 \%$ for $\mathrm{AMH}$ assay. 
Effect of Metformin Therapy Over Hormone Profile in Newly Diagnosed Polycystic Ovary Syndrome -A Nine Months Randomized Controlled Trial

\section{Statistical Methods}

All data are processed by the SPSS program (version-22.0). Values are expressed as frequencies or mean \pm SD unless mentioned otherwise. At the end of the study, metformin/placebo was unblinded and subjects were divided into two groups: one metformin and another as placebo. Within each group categorical variables (hirsutism, acne, acanthosis nigricans, menstrual irregularity, infertility) were analyzed by using Chi square. Numerical variables (serum AMH, testosterone, progesterone) were analyzed by paired or unpaired t-test as applicable. P-values $\leq 0.05$ were considered as significant.

\section{RESULTS}

Randomized double blind placebo-controlled study was done on PCOS to see the effect of metformin for which 80 subjects (age, mean \pm SD: $23.10 \pm 4.30$; married/unmarried: 44/36; H/O amenorrhea/oligomenorrhea: 90\%; H/O abortion: 25\%; H/O infertility: 38.6\%). Characteristics of the subject are shown in Table-I. Metformin or placebo were continued for 9 months in each subjects with intermittent follow-up with periods of one month, two months and three months for last two consecutive visits. Comparison of biochemical parameters were done between the baseline findings and that after nine months by paired model of statistical test within the group and unpaired model for between the groups. Table-II shows the baseline clinical characteristics between metformin and placebo groups [metformin vs. placebo, BMI (kg/m2) 26.18 \pm 5.44 vs. 25.30 \pm 5.32 , p = 0.462; WC (cm): $86.90 \pm 12.34$ vs. $85.88 \pm 11.02, \mathrm{p}=0.696$; SBP (mmHg): $110.88 \pm 11.43$ vs.110.88 $\pm 8.47, \mathrm{p}=1.0$; DBP (mmHg): 74.38 \pm 8.56 vs.73.75 $\pm 6.96, \mathrm{p}=0.721$; hirsutism: $82.5 \%$ vs.85.0\%, p = 0.762; acne: $42.5 \%$ vs.40.0\%, $p=0.820$; acanthosis nigricans: $22.5 \%$ vs. $37.5 \%, p=0.143]$. None of the variables showed any statistical significant difference between the groups. Background hormonal and biochemical profiles (mean \pm SEM) of the patients are shown in Table-III [metformin vs. placebo, S. prolactin $(\mathrm{ng} / \mathrm{ml}): 14.54 \pm 2.78$ vs.11.84 $\pm 1.13, \mathrm{p}=$ 0.373 ; S.TSH (mIU/L): $2.44 \pm 0.20$ vs. $2.46 \pm 0.22, \mathrm{p}=0.956$; S.LH (U/L): $8 \pm 0.90$ vs. $7.24 \pm 0.88, \mathrm{p}=0.547$; . FSH $(\mathrm{U} / \mathrm{L}): 4.75 \pm 0.24$ vs. $4.61 \pm 0.39, \mathrm{p}=0.752 ; \mathrm{LH} / \mathrm{FSH}$ ratio: $1.74 \pm 0.18$ vs. $2.09 \pm 0.33, \mathrm{p}=0.338$; . testosterone (ng/ $\mathrm{ml}$ ): $8.23 \pm 0.62$ vs. $8.34 \pm 0.46, \mathrm{p}=0.893$; S.AMH (ng/ml): $5.19 \pm 0.79$ vs. $5.21 \pm 0.64, \mathrm{p}=0.986$; S. progesterone (ng/ml): $1.96 \pm 0.56$ vs. $1.67 \pm 0.51, \mathrm{p}=0.707$; fasting blood glucose (mmol/L): $4.67 \pm 0.06$ vs. $4.8 \pm 0.07, \mathrm{p}=0.195$; SGPT(U/L): $45.23 \pm 2.41$ vs. $44.90 \pm 2.94, \mathrm{p}=0.729$; S. creatinine (mg/dl): $0.79 \pm 0.02$ vs. $0.80 \pm 0.03, \mathrm{p}=0.338$ ]. It was also observed in this aspect that there was no statistical difference between the metformin and placebo groups. Fig- 1 depicts changes of hormonal profiles (mean \pm SD) before and after treatment of metformin [AMH (ng/ml): $6.10 \pm 5.68$ vs. $8.67 \pm 4.27, \mathrm{p}<0.003$; progesterone $(\mathrm{ng} / \mathrm{ml}): 1.55 \pm 2.58$ vs. $5.16 \pm 5.20, \mathrm{ng} / \mathrm{ml}, \mathrm{p}=0.006$; testosterone $(\mathrm{ng} / \mathrm{ml}): 8.11 \pm 3.98 \mathrm{vs} .5 .96 \pm 1.72, \mathrm{ng} / \mathrm{ml}, \mathrm{p}=0.003$ ]. It was found that in metformin group AMH level increased significantly as well as progesterone level whereas testosterone significantly decreased. Hormonal profiles before and after treatment by placebo are shown in Table-IV [AMH (ng/ml): 4.89 \pm 3.70 vs 10.54 \pm 3.58 , $\mathrm{p}<0.001$; testosterone $(\mathrm{ng} / \mathrm{ml}): 8.88 \pm 3.10$ vs. $8.86 \pm 3.06, \mathrm{ng} / \mathrm{ml}, \mathrm{p}=0.989$; progesterone $(\mathrm{mg} / \mathrm{ml}) 0.94 \pm 0.85$ vs $0.82 \pm 1.34, \mathrm{ng} / \mathrm{ml}, \mathrm{p}=0.670]$. AMH $(\mathrm{ng} / \mathrm{ml})$ was increased after nine months whereas testosterone and progesterone unchanged statistically.

Comparison between the metformin and placebo groups for the hormonal profiles at the end point of the study is shown Fig-2. Though in both groups, AMH happened to be increased than baseline it was relatively more increased in the placebo group $(8.67 \pm 4.27$ vs. $10.54 \pm 3.58, \mathrm{ng} / \mathrm{ml}, \mathrm{p}=0.106)$. However increase of progesterone $(5.16 \pm 5.20$ vs. $0.82 \pm 1.33, \mathrm{ng} / \mathrm{ml}, \mathrm{p}<0.001)$ and reduction of testosterone $(5.96 \pm 1.71$ vs. $8.86 \pm 3.09, \mathrm{ng} / \mathrm{ml}$, $\mathrm{p}<0.001$ ) were statistically significant and comparable between metformin and placebo groups. 
Effect of Metformin Therapy Over Hormone Profile in Newly Diagnosed Polycystic Ovary Syndrome -A Nine Months Randomized Controlled Trial

Table I. Characteristics of the study population at baseline $(n=80)$

\begin{tabular}{|c|c|c|c|c|}
\hline Characteristics & All & Metformin & Placebo & $\mathbf{P}$ \\
\hline $\mathrm{n}$ & 80 & 40 & 40 & \\
\hline Age $(m \pm S D)$ & $23.10 \pm 4.30$ & $23.54 \pm 5.14$ & $22.67 \pm 3.27$ & 0.373 \\
\hline \multicolumn{5}{|l|}{ Occupation } \\
\hline House wife & $35(43.8 \%)$ & $17(42.5 \%)$ & $18(45.0 \%)$ & \multirow{3}{*}{0.973} \\
\hline Service holder & $6(7.5 \%)$ & $3(7.5 \%)$ & $3(7.5 \%)$ & \\
\hline Student & $39(48.8 \%)$ & $20(50.0 \%)$ & $19(47 \%)$ & \\
\hline \multicolumn{4}{|l|}{ Marital status } & \multirow{3}{*}{1.0} \\
\hline Married & $44(55 \%)$ & $22(55 \%)$ & $22(55 \%)$ & \\
\hline Unmarried & $36(45 \%)$ & $18(45.0 \%)$ & $18(45.0 \%)$ & \\
\hline $\begin{array}{l}\text { H/O Amenorrhea/ } \\
\text { oligomenorrhea }\end{array}$ & $72(90 \%)$ & $34(85.0 \%)$ & $36(90.0 \%)$ & 0.638 \\
\hline H/O MR/Abortion* & $11(25 \%)$ & $7(31.8 \%)$ & $4(18.2 \%)$ & 0.296 \\
\hline H/O Infertility* & 17(38.6\%) & $6(27.3 \%)$ & $11(50.0 \%)$ & 0.219 \\
\hline
\end{tabular}

(Within parenthesis are percentages over column total)

Significant values stand for comparison between metformin and placebo by student $t$-test and chi-square test

Total dropped cases were $=27$, who did not complete study

( metformin $=26$, placebo $=23$, Primary endpoint due to pregnancy $=4$ )

$m \pm S D:$ mean \pm standard deviation

H/O: history of

*Only married respondents $(n=44)$

Table II. Baseline clinical characteristics of the study subjects

\begin{tabular}{|c|c|c|c|c|}
\hline Variales & All subjects & Metformin & Placebo & p \\
\hline $\mathrm{n}$ & 80 & 40 & 40 & \\
\hline $\mathrm{BMI}\left(\mathrm{Kg} / \mathrm{m}^{2}\right)$ & $25.74 \pm 5.37$ & $26.18 \pm 5.44$ & $25.30 \pm 5.32$ & 0.462 \\
\hline WC(centimeter) & $86.39 \pm 11.64$ & $86.90 \pm 12.34$ & $85.88 \pm 11.02$ & 0.696 \\
\hline Systolic BP & $110.9 \pm 9.99$ & $110.88 \pm 11.43$ & $110.88 \pm 8.47$ & 1.0 \\
\hline Diastolic BP & $74.0 \pm 7.76$ & $74.38 \pm 8.56$ & $73.75 \pm 6.96$ & 0.721 \\
\hline Hirsutism & $67(83.8 \%)$ & $33(82.5 \%)$ & $34(85.0 \%)$ & 0.762 \\
\hline Acne & $33(41.3 \%)$ & $17(42.5 \%)$ & $16(40.0 \%)$ & 0.820 \\
\hline Acanthosis nigricans & $24(30 \%)$ & $9(22.5 \%)$ & $15(37.5 \%)$ & 0.143 \\
\hline
\end{tabular}

(Data were expressed as frequency, percentage, mean $\pm S D$ )

Independent student $t$-test was performed to compare between two groups for quantitative data

Chi-square test was performed to compare between two groups for qualitative data 
Effect of Metformin Therapy Over Hormone Profile in Newly Diagnosed Polycystic Ovary Syndrome -A Nine Months Randomized Controlled Trial

BMI: body mass index

$\mathrm{Kg} / \mathrm{m}^{2}:$ kilogram $/$ meter $^{2}$

WC : waist circumference

BP: blood pressure

Table III. Baseline hormonal and biochemical profiles of the study patients

\begin{tabular}{|c|c|c|c|c|}
\hline $\begin{array}{c}\text { Hormonal and } \\
\text { Biochemical profiles }\end{array}$ & $\begin{array}{c}\text { Total } \\
(\mathbf{n = 8 0})\end{array}$ & $\begin{array}{c}\text { Metformin } \\
\text { (n= 40) }\end{array}$ & $\begin{array}{c}\text { Placebo } \\
\text { (n= 40) }\end{array}$ & p \\
\hline S. Prolectin(ng/ml) & $13.18 \pm 1.50$ & $14.54 \pm 2.78$ & $11.84 \pm 1.13$ & 0.373 \\
\hline S. TSH(mIU/L) & $2.45 \pm 0.15$ & $2.44 \pm 0.20$ & $2.46 \pm 0.22$ & 0.956 \\
\hline S. $\mathrm{LH}(\mathrm{U} / \mathrm{L})$ & $7.62 \pm 0.63$ & $8 \pm 0.90$ & $7.24 \pm 0.88$ & 0.547 \\
\hline S. FSH(U/L) & $4.68 \pm 0.23$ & $4.75 \pm 0.24$ & $4.61 \pm 0.39$ & 0.752 \\
\hline LH/FSH ratio & $1.91 \pm 0.18$ & $1.74 \pm 0.18$ & $2.09 \pm 0.33$ & 0.338 \\
\hline S. Testosterone(ng/ml) & $8.29 \pm 0.38$ & $8.23 \pm 0.62$ & $8.34 \pm 0.46$ & 0.893 \\
\hline S. AMH(ng/ml) & $4.97 \pm 0.47$ & $5.19 \pm 0.79$ & $5.21 \pm 0.64$ & 0.986 \\
\hline S. Progesterone(ng/ml) & $1.82 \pm 0.37$ & $1.96 \pm 0.56$ & $1.67 \pm 0.51$ & 0.707 \\
\hline $\begin{array}{c}\text { Fasting blood } \\
\text { glucose(mmol/L) }\end{array}$ & $4.73 \pm 0.49$ & $4.67 \pm 0.06$ & $4.8 \pm 0.07$ & 0.195 \\
\hline SGPT(U/L) & $45.56 \pm 1.89$ & $46.23 \pm 2.41$ & $44.90 \pm 2.94$ & 0.729 \\
\hline S. Creatinine(mg/dl) & $0.79 \pm 0.16$ & $0.79 \pm 0.02$ & $0.80 \pm 0.03$ & 0.338 \\
\hline
\end{tabular}

Data were expressed as mean \pm SEM

Independent student $t$-test was performed to compare between two groups

TSH: thyroid stimulating hormone

LH: luteinizing hormone

FSH: follicle stimulating hormone

AMH: anti-mullerian hormone

Table IV. Level of AMH, testosterone and progesterone before and after treatment in placebo group $(n=23)$

\begin{tabular}{|l|c|c|c|}
\hline Hormone profile & $\begin{array}{c}\text { Before treatment } \\
(\mathbf{n = 2 3})\end{array}$ & $\begin{array}{c}\text { After treatment } \\
(\mathbf{n = 2 3 )}\end{array}$ & $\mathbf{p}$ \\
\hline AMH $(\mathrm{ng} / \mathrm{ml})$ & $4.89 \pm 3.70$ & $10.54 \pm 3.58$ & $<0.001$ \\
\hline Testosterone $(\mathrm{ng} / \mathrm{ml})$ & $8.88 \pm 3.10$ & $8.86 \pm 3.06$ & 0.989 \\
\hline Progesterone $(\mathrm{ng} / \mathrm{ml})$ & $0.94 \pm 0.85$ & $0.82 \pm 1.34$ & 0.670 \\
\hline
\end{tabular}

Data were expressed as mean $\pm S D$

Paired sample t-test was performed to compare within group

AMH = anti-mullerian hormone 
Effect of Metformin Therapy Over Hormone Profile in Newly Diagnosed Polycystic Ovary Syndrome -A Nine Months Randomized Controlled Trial

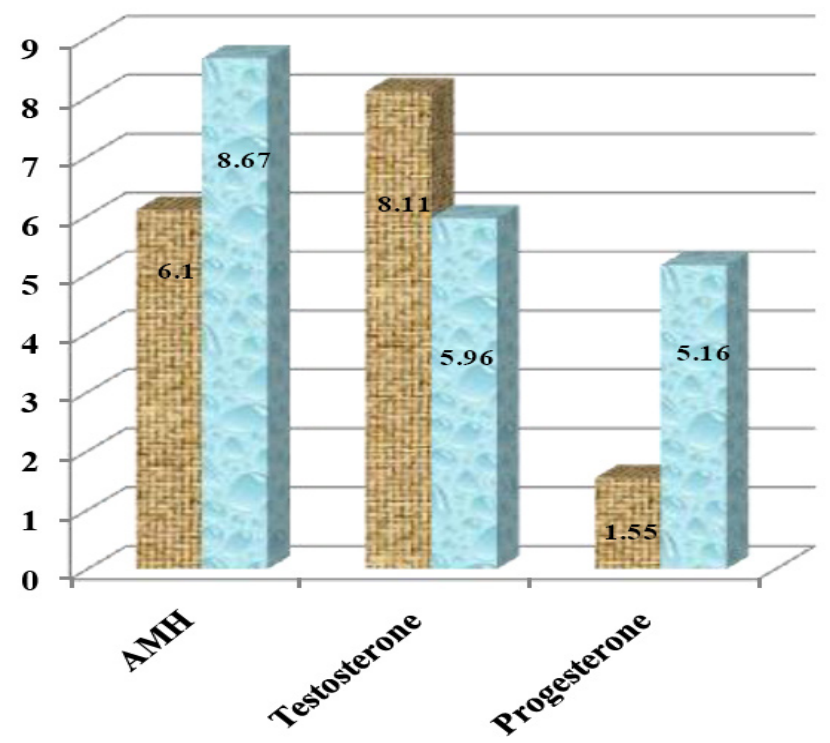

\section{Before treatment \\ After treatment}

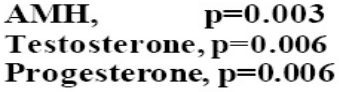

Progesterone, $\mathrm{p}=0.006$

Fig1. Level of AMH ( $\mathrm{ng} / \mathrm{ml})$, testosterone $(\mathrm{ng} / \mathrm{ml})$ and progesterone $(\mathrm{ng} / \mathrm{ml})$ before and after treatment in metformin group $(n=26)$

AMH: anti-mullerian hormone

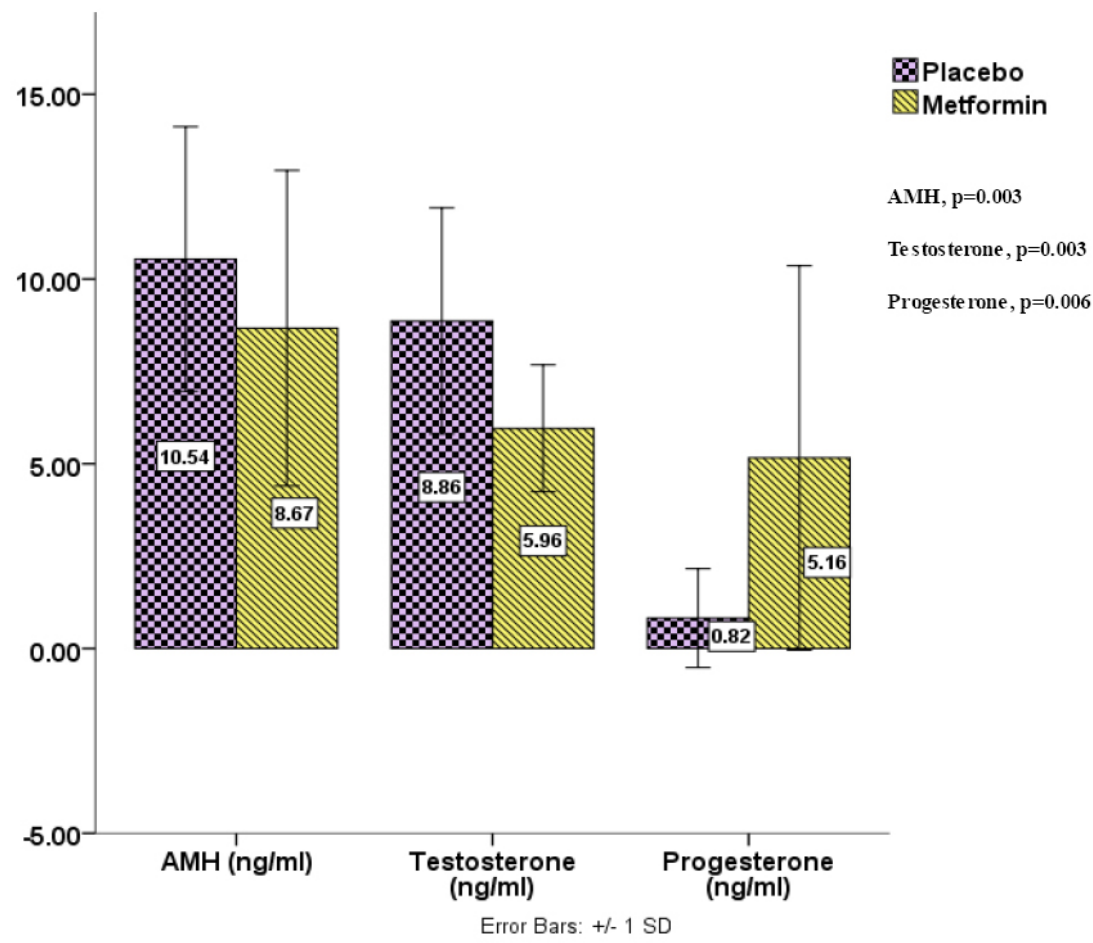

Fig 2. Level of AMH, testosterone and progesterone after last visit between placebo and metformin groups AMH: anti-mullerian hormone 
Effect of Metformin Therapy Over Hormone Profile in Newly Diagnosed Polycystic Ovary Syndrome -A Nine Months Randomized Controlled Trial

\section{DiscUSSION}

PCOS is not an uncommon disorder affecting many women in reproductive age. Recognition of insulin resistance as an important factor in the pathogenesis of PCOS instigated a wide use of insulin sensitizing agents for the treatment of the problem. ${ }^{13}$ Among the insulin sensitizers, metformin is the most commonly used agent which is preferred for the treatment of PCOS. ${ }^{14}$ Though the beneficial effect of metformin has been proposed and advocated by many authorities, it has not been substantiated in wide scale by RCT.

In this study a similar baseline clinical and biochemical characteristics are present between metformin and placebo groups. Similar to the baseline clinical characteristic, biochemical and hormonal profiles were statistically non-different between the two groups at initiation of the study. Comparing within group, significant reduction of androgenic activity was observed in the metformin group but not in the placebo after nine months of treatment. Likewise, mean progesterone level in the third week of cycle or nearby time in the last month improved significantly in the metformin group but not in placebo. Contrary to the common belief and unlike androgen, in both groups, AMH increased significantly which was more in placebo. Menstrual regulation significantly improved after treatment with metformin as well as placebo but more with metformin. Though not significantly different from the placebo group, the adverse events were more frequent with the metformin group.

Significant heterogeneity in the hormonal response after metformin was observed. ${ }^{15,16,17,18}$ The present study observed reduction of testosterone whereas increase of progesterone and AMH level in metformin group; but in placebo there was no significant change in testosterone and progesterone level. However, AMH level raised significantly and with higher magnitude than that of metformin in the placebo group. Velazquez and colleagues $(1994)^{14}$ reported in an observational study a significant improvement in menstrual regularity and reduction of circulating androgen levels as well as significant reduction of body weight. Yu Ng et al. (2001) ${ }^{19}$ found that serum testosterone concentration was significantly reduced in the metformin group after 3 months and there was a significant increase of serum testosterone in placebo group. ${ }^{20}$ This view is supported by others also. ${ }^{8,14,15,19,21}$

In the present study, despite the improvement of metabolic parameters and reduction of androgen levels, AMH levels increased after treatment, more with placebo than metformin group. Tomava et al. $(2011)^{16}$ found discrepant levels of AMH level after metformin therapy; some showing decrease and some having increased or no change. Nascimento et al. (2013) found no alteration in AMH levels after treatment. ${ }^{17}$ The dose and duration of metformin therapy needs to be optimized for getting the benefit.

Regarding the side effects, as expected metformin was more associated with minor gastrointestinal events. However, neither in the metformin group nor in the placebo group, there were any serious adverse events.

In conclusion, the present double blind placebo-controlled RCT of nine months period by metformin on PCOS revealed that the drug has significant beneficial effect on the androgenic activity. There was no remarkable adverse event caused by the drug. AMH was not found to be reduced, rather increased after nine months treatment by metformin in a dose of $1500 \mathrm{mg} /$ day or by placebo.

\section{REFERENCES}

1. Godus VT, Dumesic DA. Polycystic ovary syndrome. Endocrinol Metab clin North Am 1997; 24: 893-91.

2. Fleming R, Hopkinson ZE, Wallace AM, Greer IA, Satter N. Ovarian function and metabolic factors in women with oligomenorrhea treated with metformin in a randomized double-blind placebo-controlled trial. J clin Endocrinal Metab 2002; 87: 569-574. 
Effect of Metformin Therapy Over Hormone Profile in Newly Diagnosed Polycystic Ovary Syndrome -A Nine Months Randomized Controlled Trial

3. Hahn S, Quadbeck B, Elsenbruch S, Gartner R, Finke R, Mann K. Metformin an efficacious drug in the treatment of polycystic ovary syndrome. Dtsch Med Wochenscha 2004; 129: 1059-1064.

4. The Rotterdam ESHRE/ASRM-sponsored PCOS consensus workshop group. Revised 2003 consensus on diagnostic criteria and long term health risks related to polycystic ovary syndrome. Fertil steril 2003; 81: 19-25.

5. Tokako, Araki, Rony, Elia, Zev, Rosenwaks, Leonid, Poretsky. Achieving a successful pregnancy in women with polycystic ovary syndrome. Endocrinology\&metabolism clinics of North America 2011; 40: 866-83.

6. Homburg R. Should patients with polycystic ovarian syndrome be treated with metformin? Hum.Repord 2002; 17: 853-856.

7. Nestler J, Stovall D, Akhter N, Iuorono M, Jakubowicz D. Strategies for the use of insulin-sensitizing drugs to treat infertility in women with polycystic ovary syndrome. Fertil steril 2002; $77: 209$.

8. Glueck C, Wang P, Koyabash S. Metformin therapy throughout pregnancy reduces development of gestational diabetes in women with polycystic ovarian syndrome. Fertil steril 2002; 77: 520-525.

9. Guzick D. Polycystic ovary syndrome: symptomatology, pathophysology and epidemiology. Am.J.Obstet, Gynecol 1998; 179: 589-593.

10. Ortega-Gonzalez C, Luna S, Hernandez l, Crespo G, Aguayo P, Parra A. Responses of serum androgen and insulin resistance to metformin and pioglitazone in obese insulin-resistant women with polycystic ovary syndrome. J Clin Endocrinol Metab 2005; 90: 1360-5.

11. Amin M, Abdel-Kareem, O, Takekida, S, Moriyama, T, Abedel-Aal G, Maruo T. Minireview: update management of non-responder to clomiphene citrate in polycystic ovary syndrome. Kobe J Med Sci 2003; 49: 59-73.

12. Diamanti-Kandarak E, Zapanti E. Insulin sensitizers and anti-androgen in the of polycystic ovary syndrome. Ann NY Acad Sci 2000; 900: 203-12.

13. Nestler JE. Metformin for the treatment of the polycystic ovary syndrome. N Engl J Med 2008; 358: 47-54.

14. Velazquez EM, Mendoza SG, Hamer T, Sosa F, Glueck CJ, 1994.Metformin therapy in polycystic ovary syndrome reduces hyperinsulinemia, insulin resistance, hyperandrogenemia and systolic blood pressure, while facilitating normal menses and pregnancy. Metabolism 1994;vol : 647-654. DOI: http: //dx. Doi. Org/10.1016/0026-0495(94) 90209-7.

15. Moghetti P, Castello R, Negri C, Tosi F, Perrone F, Caputo MZ, Anolin E, Muggeo M. Metformin effects on clinical features, endocrine and metabolic profiles, and insulin sensitivity in polycystic ovary syndrome: a randomized, double-blind, placebo-controlled 6-month trial, followed by open, long-term clinical evaluation. The Journal of Clinical Endocrinology \&Metabolism 2000; 85: 139-146.

16. Tomava A, Deepinder F, Robeva R, Kirilov G, Mechandjiev, Kumanov P. Anti-Mullerian hormone in women with polycystic ovary syndrome before and after therapy with metformin. Horm METAB 2011; 43: 723-7.

17. Nascimento AD, Silva Lara LA, Japur de Sa Rosa-e-Silva AC, Ferriani RA, Reis RM. Effects of metformin on serum insulin and anti-Mullerian hormone levels and on hyperandrogenism in patients with polycystic ovary syndrome. Gynecol Endocrinol 2013; 29: 246-9.

18. Moran LJ, Noakes M, Clifton PM, Norman RJ. The use of anti-mullerian hormone in predicting menstrual response after weight loss in overweight women with polycystic ovary syndrome. J Clin Endocrinol Metab 2007; 92: 3796-802. 
Effect of Metformin Therapy Over Hormone Profile in Newly Diagnosed Polycystic Ovary Syndrome -A Nine Months Randomized Controlled Trial

19. Yu Ng EH, Sum Wat NM, Ho PC. Effects of metformin on ovulation rate, hormonal and metabolic profiles in women with clomiphene-resistant polycystic ovaries: a randomized, double-blinded placebo-controlled trial. Human Reproduction 2001; 16:1625-1631.

20. Nazari T, Bayat R, Hamedi M. Metformin therapy in girls with polycystic ovary syndrome: a self-controlled clinical trial. Arch Iranian Med 2007; 10: 176-181.

21. Pasquali R, Gambineri A. Treatment of hirsutism in the polycystic ovary syndrome. European Journal of Endocrinology 2014; 170:75-90.

22. Bridger T, MacDonald S, Baltzer F, Rodd C. Arch Pediatr Adolesc Med 2006; 160: 241-6.

Citation: Nazma-Akhtar, M A Hasanat, Hurjahan-Banu, Sadiqa-Tuqan, Marufa-Mustari, Tania-Sultana, Md Fariduddin. "Effect of Metformin Therapy Over Hormone Profile in Newly Diagnosed Polycystic Ovary Syndrome -A Nine Months Randomized Controlled Trial". American Research Journal of Endocrinology; 1(1): 9-17

Copyright (c) Nazma-Akhtar, M A Hasanat, Hurjahan-Banu, Sadiqa-Tuqan, Marufa-Mustari, Tania-Sultana, Md Fariduddin, This is an open access article distributed under the Creative Commons Attribution License, which permits unrestricted use, distribution, and reproduction in any medium, provided the original work is properly cited. 